\title{
INOVAÇÃO TECNOLÓGICA NA CONSTRUÇÃO CIVIL
}

TECHNOLOGICAL INNOVATION IN CONSTRUCTION

\author{
Ariovaldo Denis Granja 1 \\ Universidade Estadual de Campinas, \\ Faculdade de Engenharia Civil, Arquitetura \\ e Urbanismo, \\ Campinas - SP \\ Editor Convidado \\ adgranja@fec.unicamp.br
}

\section{Editorial}

Esta edição da Revista PARC Pesquisa em Arquitetura e Construção tem como principal tema a inovação tecnológica na construção civil. Em outros setores industriais, o termo inovação descreve um processo que se estende desde a criação de uma ideia até a inserção no mercado de um novo produto, processo ou serviço. O gerenciamento da inovação combina elementos soft, tais como a geração e análise de ideias, e também hard, mais focados em gerenciamento de projetos (project management) e na velocidade de inserção no mercado (MAXWELL, 2009). No entanto, na construção civil a introdução de novos sistemas, processos construtivos e componentes de construção é vista como o principal indutor de mudança tecnológica (REICHSTEIN; SALTER; GANN, 2005).

No Brasil, o universo acadêmico e os setores privados e públicos têm reconhecido a importância da formulação de uma política de ciência, tecnologia e inovação para modernizar o setor da construção civil (CARDOSO, 2013). Considerando-se a complexidade inerente de seus produtos, o desafio é enorme (WINCH, 1998). Decorre daí que muitas empresas do setor ainda parecem se conformar com os baixos níveis de desempenho tecnológico, financeiro e econômico, assumindo-os como características intrínsecas, o que dificulta a dinâmica de indução da inovação tecnológica. A divulgação de exemplos e de seus mecanismos subjacentes pode incentivar a reversão destas percepções.

Nesta edição da PARC, cinco artigos oferecem uma variedade de perspectivas relacionadas à inovação. Estes artigos trazem exemplos e também mecanismos de indução de inovação tecnológica voltados à indústria da construção civil. A cobertura temática inclui exemplos de sistemas construtivos ainda pouco estabelecidos na prática, o uso de modelagem da informação da construção (BIM) na gestão de facilidades, uma experiência didática de ensino por meio do uso de maquetes em escala 1:1 e considerações sobre a efetividade da transferência de conhecimentos de treinamentos de operários até o ambiente de trabalho.

O primeiro artigo, cujos autores são Luana Toralles Carbonari e Fernando Barth - do Centro Universitário Filadélfia de Londrina e da Universidade Federal de Santa Cantarina - apresenta um estudo sobre a reutilização de

How to cite this article:

GRANJA, Ariovaldo Denis. Inovação tecnológica na construção civil. PARC Pesquisa em Arquitetura e Construção, Campinas, SP, v. 6, n. 4, p. 252254, dez. 2015. ISSN 1980-6809. Disponível em: <http://periodicos.sbu.unicamp.br/ojs/index.php/parc/article/view/8644407>. Acesso em: 19 mar. 2016. doi:http://dx.doi.org/10.20396/parc.v6i4.8644407. 
contêineres para a construção de edifícios comerciais. Não obstante já se observar o uso deste sistema construtivo em alguns países, inclusive no Brasil, pouco conhecimento sistematizado existe sobre as recomendações e cuidados para a sua reutilização em edifícios comerciais. O artigo traz uma avaliação sobre os principais parâmetros relacionados a este sistema construtivo e as adequações necessárias para uso em edificações comerciais localizadas na região sul do país. Adicionalmente, são abordados aspectos relacionados à logística operacional e aos procedimentos necessários para a adequações dos contêineres. A pesquisa sinaliza a viabilidade técnica de seu uso na construção de edifícios, com prováveis benefícios agregados em termos de racionalização construtiva e sustentabilidade.

$\mathrm{O}$ uso da realidade aumentada (RA) via head mounted display (HMD) sem fio como auxílio na montagem de painéis estruturados de madeira no sistema construtivo wood-frame é a temática explorada no segundo artigo. Ana Regina Mizrahy Cuperschmid, Marina Graf Grachet e Márcio Minto Fabrício - da Universidade de São Paulo - utilizam a RA para a visualização da sequência de montagem dos painéis, a partir de um modelo concebido por meio de BIM. Os autores avaliam a qualidade das experiências dos usuários com o uso desta tecnologia e concluem pela aceitação e interesse de maneira geral. Também apontam oportunidades de melhorias para aplicações futuras. Complementarmente à potencialidade identificada de seu uso no sistema woodframe, os autores vislumbram maior abrangência de aplicação, também desdobrada para outros sistemas construtivos.

O impacto da adoção de BIM na gestão de facilidades (facility management) é bem ilustrado no terceiro artigo, o qual compara as transformações no fluxo de gestão de facilidades com e sem o uso deste processo. Lorena Claudia de Souza Moreira e Regina Coeli Ruschel - da Universidade Estadual de Campinas - verificam três situações impactantes da incorporação de BIM na gestão de facilidades, as quais são: no próprio processo, no sistema de gestão de facilidades e na troca de informações. Para fins da incorporação de BIM em gestão de facilidades, as autoras recomendam um processo de mudança gradual e planejado nestas três situações, o qual deve ser precedido por uma classificação prévia do cenário em que se encontra a empresa interessada. Este procedimento pode auxiliar a tomada de decisão de interessados na implantação de BIM em gestão de facilidades ou mesmo avaliar esforços já realizados neste sentido.

O percurso desde o projeto até a execução de uma habitação mínima é ilustrado no quarto artigo, ao longo do qual mock-ups em escala 1:1 são desenvolvidos por alunos de arquitetura e urbanismo. Além da execução propriamente dita do elemento complexo, as autoras Maria Isabel Imbronito e Eneida de Almeida - da Universidade São Judas Tadeu - enaltecem que a abordagem também possibilita a experiência de ocupar e perceber o espaço construído. Diversas formas de experimentação e verificação in loco são vivenciadas por meio da construção dos mock-ups, as quais estabelecem vínculos simultâneos com diversas prerrogativas de projeto. As autoras ainda indicam novas oportunidades de pesquisas acerca da relação entre a matéria e o espaço no âmbito do ensino do projeto de arquitetura, bem como dos aperfeiçoamentos do sistema construtivo vivenciado.

No quinto e último artigo desta edição, Ana Maria de Sousa Santana de Oliveira e Ricardo Rocha de Oliveira - da Universidade Estadual do Oeste do Paraná analisam estatisticamente a transferência de conhecimentos recebidos em programas de treinamento por trabalhadores de obras. Os autores empregam protocolos de observação direta e submetem os dados a análises quantitativas e testes estatísticos. Em relação a outros trabalhos acadêmicos, o processo de avaliação utiliza uma abordagem mais complexa com relação ao critério de sucesso na transferência de conhecimentos. Deste modo, a abordagem utilizada pelos autores realiza as observações sobre a efetividade do uso dos conhecimentos e das habilidades adquiridas em períodos posteriores ao da realização da atividade. O procedimento apresentado pode servir como ferramenta de diagnóstico sobre a efetividade do uso dos novos conhecimentos e habilidades adquiridas, bem como subsidiar eventuais modificações em módulos ou etapas de treinamento.

Esta edição poderá interessar particularmente a profissionais e acadêmicos que se dedicam ao desenvolvimento de sistemas e componentes construtivos, ao uso de BIM e RA, ao emprego de maquetes no ensino de arquitetura e urbanismo e à gestão do conhecimento de trabalhadores de obras. Gostaria de agradecer aos avaliadores dos artigos desta edição o grande trabalho desenvolvido e os respectivos 
compromissos com o rigor acadêmico. O resultado final dos artigos contidos nesta edição resulta do empenho diligente dos autores na incorporação dos comentários e sugestões oferecidas pelos revisores. Desejo a todos uma boa leitura.

\section{Referências}

CARDOSO, Francisco Ferreira. Estratégias para a formulação de política de ciência, tecnologia e inovação para a indústria da construção civil. São Paulo: Associação Nacional do Ambiente Construído, 2013.

MAXWELL, Ian. Managing sustainable innovation: The driver for global growth. New York: Springer, 2009. 154 p.

REICHSTEIN, Toke; SALTER, Ammon J.; GANN, David M. Last among equals: a comparison of innovation in construction, services and manufacturing in the UK. Construction Management and Economics, [s.1.], v. 23, n. 6, p.631644, jul. 2005. Informa UK Limited. http://dx.doi.org/10.1080/01446190500126940.

WINCH, Graham. Zephyrs of creative destruction: understanding the management of innovation in construction. Building Research \& Information, [s.1.], v. 26, n. 5, p.268-279, set. 1998. Informa UK Limited. http://dx.doi.org/10.1080/096132198369751.

\footnotetext{
${ }^{1}$ Ariovaldo Denis Granja

Engenheiro Civil. Doutor em Engenharia Civil. Professor Doutor II (UNICAMP). Endereço postal: Av. Albert Einstein, 951, Campinas, SP, Brasil, CEP 13.083-852.
} 